\title{
Exploring the Factors for Marketing Indoor Cycling
}

\author{
Javier A. Monterrosa \\ Marketing Department, \\ Bentley University, Waltham, MA, USA \\ Paul D. Berger \\ Marketing Department, \\ Bentley University, Waltham, MA, USA
}

\begin{abstract}
In this paper, we use multiple regression and stepwise regression analyses to consider a set of variables to determine what is important in the marketing of, and actual use, of indoor cycling. We find that the importance of music to the consumer, and the importance of cleanliness of the studio to the consumer are key factors in the amount of use a consumer makes of indoor cycling. We also discuss entertainment marketing and the role of sense of community.
\end{abstract}

Key Words: Indoor cycling, Entertainment marketing, Stepwise regression analysis, The role of music, The sense of community.

\section{INTRODUCTION}

As of 2018, the Gym, Health \& Fitness Clubs industry has been valued at $\$ 33.7$ billion and it is set to increase 1.5\% year-over-over until 2023 (Cohen, 2018). With such a booming industry, studios of all sorts are opening in every major city around the world. There are several reasons why this is happening, such as increased health insurance costs, increased demand for healthy foods, higher access to fitness wearables, among other reasons (Midgley, 2018). Indoor spinning studios are an example of these studios that have benefited from the growing trend of a healthy lifestyle.

Indoor cycling studios generate 55\% more revenue than any other kind of studio (Leve, 2016). For this reason, companies like SoulCycle, Flywheel, and Peloton have been successful, despite charging anywhere from $\$ 30$ per class (SoulCycle, 2018) to $\$ 2,245$ to purchase a stationary bike and have customers pay an additional $\$ 39$ subscription fee per month to exercise in the comfort of their homes (Peloton, 2018). How is this possible? According to a study conducted by Deloitte, fitness studios are capable of doing this, since consumers have "shifted from purchasing 'things' to purchasing 'experiences' " (Barua and Bachman, 2017). Indoor cycling studios are all about the experience, mainly building a sense of community among their riders, which is why most studios have succeeded. However, with many indoor cycling studios already existing, studios need to now focus on differentiation in order to survive.

Differentiation in today's world is important as well as having consumers at the center of every business strategy, better known as customer centricity (Deshpande, 2014). Therefore, indoor cycling studios need to craft a value proposition that is different from others' in order to keep their business. For this reason, the focus of this research is to determine what attributes of a studio are most important to customers in order to help existing or future indoor cycling studio owners focus on those attributes, ultimately, related to marketng, that impact a customer's desire to cycle. To do so, a stepwise regression analysis will be applied to attributes 
identified through a survey in order to find which of the variables are significant at predicting the likelihood of a customer (rider) visiting a studio more often.

\section{Spending on Experiences}

\section{LITERATURE REVIEW}

Research conducted by scholars such as Leonardo Nicolao, Julie R. Irwin and Joseph K. Goodman (2009), looked into whether or not experiential purchases made people happier than material purchases. This experiment was conducted at the University of Texas at Austin and involved 211 undergraduate students. A questionnaire was administered, asking students a series of questions such as describing a time they made a purchase of approximately $\$ 300$. Researchers found that "experiential purchases led to more happiness if there was a positive outcome..." (Nicolao et al., 2009). This study was an adaptation of a previous study conducted in 2003 by Leaf Van Boven and Thomas Gilovich (2003) called To Do or To Have? That Is The Question.

A second experiment was held by these same researchers, this time with 198 undergraduate and MBA students at the same university. For this experiment, participants were asked to recall three purchases that resulted in a positive or negative emotion. Results showed the same outcome: experiential purchases led to more happiness for those participants who had a positive outcome from the purchase and considered themselves less materialistic. However, results from Nicolao et al. in both experiments did not address the potential effect of "accumulated purchase patterns on overall happiness" (Nicolao et al., 2009).

\section{Attributes of Successful Indoor Cycling Studios}

Knowing that consumers are less price conscious when purchases result in happiness validates the reason why fitness studios such as indoor cycling are successful. Attributes of indoor cycling studios may be a key factor leading to success. Music is one of the attributes that we explore as Harmon and Kravitz (2007) found that music has a positive impact on physical strength during exercise. Specifically, They found that music "facilitates exercise, including (1) a reduction in the feeling of fatigue, (2) an increase in levels of psychological arousal, (3) a physiological relaxation response and (4) an improvement in motor coordination" (Harmon and Kravitz, 2007). To reach these conclusions, they reviewed multiple research studies conducted by other scholars to put together a collective conclusion on the impact of music on exercise.

First, they focused on "music as a motivator in exercise performance," where it was found that "music can act as a motivator" that leads to greater exercise efficiency. However, motivations seemed to decrease with higher intensity exercises. Second, they researched "improving strength and endurance through psychological arousal," and found that music does increase psychological arousal and that the type of music also leads to different levels of arousal. The third element under review was "promoting relaxation," which found that music does lead individuals to easily get through more physically demanding exercises. Finally, looking at "improving motor coordination" found that rhythm helps individuals with the "coordination of motor skills, large and small."

\section{METHODOLOGY}

To collect the desired data, the study executed a survey with customers of FireCycle, referenced as riders. This studio has been chosen since its owner allowed for this survey to take place. This studio is located in Waltham, MA. The questionnaire was composed of a mix of questions that collected data on exercise patterns, psychographics, and demographics. These questions have a mix of nominal, interval and ratio scales. The collection of data using the survey was in-person 
at the studio location. Two class times were chosen at random to reduce any bias. We analyze the data using stepwise regression with the aid of the statistical software package, SPSS. Nominal questions were re-coded to ensure appropriate analysis.

The dependent variable of interest is the frequency a rider practices indoor cycling. The independent variables that are hypothesized to have a significant effect at predicting this frequency are the importance of: sense of community, music, and price per class. However, this study will evaluate a total of five variables including the aforementioned three variables, as well as the importance of friendliness of the staff and a rider's household income (HHI). Due to the previous study by Harmon and Kravitz (2007) on the impact of music on exercise, it is expected that the importance of music will be one of the most significant variables. Additionally, given that customers are generally price conscious, price is also expected to be another highly significant variable. Prior to the analysis, we are not certain about the significance (or not) of other variables.

\section{Descriptive Statistics}

\section{ANALYSIS AND DISCUSSIONS OF RESULTS}

Once the surveys were distributed, twenty responses were collected $(n=20)$ over the two randomly selected classes. We later acknowledge the small sample size as a major limitation of the study. In order to show the distribution of responses based on demographic data, certain data categories responses were re-coded. For age the following codes were allocated, as shown in Table 1.

\begin{tabular}{|c|c|}
\hline Age Range & Code \\
\hline $16-25$ & 1 \\
\hline $26-35$ & 2 \\
\hline $36-45$ & 3 \\
\hline $46-55$ & 4 \\
\hline 56 or older & 5 \\
\hline
\end{tabular}

Table 1: Coding of the age variable

With this recoded data Table 2 shows the age distribution of respondents.

\begin{tabular}{|c|c|c|c|c|c|}
\hline & & & AGE & & \\
\hline & & Frequency & Percent & Valid Percent & $\begin{array}{c}\text { Cumulative } \\
\text { Percent }\end{array}$ \\
\hline Valid & 1.00 & 1 & 4.8 & 5.0 & 5.0 \\
\hline & 2.00 & 10 & 47.6 & 50.0 & 55.0 \\
\hline & 3.00 & 7 & 33.3 & 35.0 & 90.0 \\
\hline & 4.00 & 1 & 4.8 & 5.0 & 95.0 \\
\hline & 5.00 & 1 & 4.8 & 5.0 & 100.0 \\
\hline & Total & 20 & 95.2 & 100.0 & \\
\hline Missing & System & 1 & 4.8 & & \\
\hline Total & & 21 & 100.0 & & \\
\hline
\end{tabular}

Table 2: Frequency distribution of age of sample

Gender was another demographic variable that was re-coded; females were coded as 0 and males were coded as 1 . The gender distribution is presented in Table 3: 
GENDER

\begin{tabular}{ll|c|c|c|c} 
& & & & Cumulative \\
& & Frequency & Percent & Valid Percent & \begin{tabular}{c} 
Percent \\
\hline Valid
\end{tabular} \\
\cline { 2 - 6 } & 1.00 & 15 & 71.4 & 75.0 & 75.0 \\
\cline { 2 - 6 } & Total & 5 & 23.8 & 25.0 & 100.0 \\
\hline Missing & System & 1 & 95.2 & 100.0 & \\
\hline Total & & 21 & 4.8 & & \\
\hline
\end{tabular}

Table 3: Frequency distribution of gender of sample

Finally, with regards to Household income (HHI), responses were recoded as shown in Table 4:

\begin{tabular}{|c|c|}
\hline HHI Range & Code \\
\hline Less than or equal to $\$ 25,000$ & 1 \\
\hline$\$ 25,001-\$ 40,000$ & 2 \\
\hline$\$ 40,001-\$ 55,000$ & 3 \\
\hline$\$ 55,001-\$ 70,000$ & 4 \\
\hline$\$ 70,001-\$ 85,000$ & 5 \\
\hline More than $\$ 85,001$ & 6 \\
\hline
\end{tabular}

Table 4: Recoded values of HHI

With this recoded data, the frequency distribution of HHI is shown in Table 5.

\begin{tabular}{|c|c|c|c|c|c|}
\hline & & & HHI & & \\
\hline & & Frequency & Percent & Valid Percent & $\begin{array}{c}\text { Cumulative } \\
\text { Percent }\end{array}$ \\
\hline Valid & 1.00 & 3 & 14.3 & 15.0 & 15.0 \\
\hline & 2.00 & 7 & 33.3 & 35.0 & 50.0 \\
\hline & 3.00 & 4 & 19.0 & 20.0 & 70.0 \\
\hline & 4.00 & 2 & 9.5 & 10.0 & 80.0 \\
\hline & 5.00 & 1 & 4.8 & 5.0 & 85.0 \\
\hline & 6.00 & 3 & 14.3 & 15.0 & 100.0 \\
\hline & Total & 20 & 95.2 & 100.0 & \\
\hline Missing & System & 1 & 4.8 & & \\
\hline Total & & 21 & 100.0 & & \\
\hline
\end{tabular}

Table 5: Frequency distribution of HHI

Based on Tables 2, 3, and 5, it is observed that respondents were mainly female, between 26 to 35 years old, with a HHI of $\$ 25,001$ to $\$ 40,000$.

\section{Definition of the Five Independent Variables of Interest}

The five independent variables included in the regression analyses were as follows:

- Sense of community: scale of 1 to 5 , where 1 is very unimportant and 5 is very important;

- Music: scale of 1 to 5 , where 1 is very unimportant and 5 is very important; 
- Cleanliness of studio $=$ scale of 1 to 5 , where 1 is very unimportant and 5 is very important;

- $\quad$ Price $=$ scale of 1 to 5 , where 1 is very unimportant and 5 is very important;

- $\mathrm{HHI}=$ re-coded to be on a scale of 1 to 6 , where $1=$ less than or equal to $\$ 25,00,2=$ $\$ 25,001-\$ 40,000,3=\$ 40,001-\$ 55,000,4=\$ 55,001-\$ 70,000,5=\$ 70,001-\$ 85,000$, $6=$ at least $\$ 85,001$;

Note that no demographic variables were included in the regression analysis except for HHI, in order to focus on the five key variables mentioned

The descriptive statistics of the independent variables are presented in Table 6:

\section{Descriptive Statistics}

\begin{tabular}{lc|c|c|c|c} 
& $\mathrm{N}$ & Minimum & Maximum & Mean & Std. Deviation \\
\hline COMMUNITY & 20 & 2.00 & 5.00 & 4.2000 & .83351 \\
\hline MUSIC & 20 & 3.00 & 5.00 & 4.4500 & .68633 \\
\hline CLEAN & 20 & 3.00 & 5.00 & 4.2500 & .55012 \\
\hline PRICE & 20 & 3.00 & 5.00 & 4.0500 & .99868 \\
\hline HHI & 20 & 1.00 & 6.00 & 3.0000 & 1.65434 \\
\hline Valid N (listwise) & 20 & & & & \\
\hline
\end{tabular}

Table 6: Descriptive statistics of the five independent variables

Based on Table 6, we can see that, on average, the importance of community, music, cleanliness, and price generally received a high response from participants. This supports the initial identifying of community, music, and price, as potentially important variables for predicting the dependent variable.

\section{Multiple-Linear Regression Analysis}

A multiple-linear regression analysis was executed with the five independent variables, and the output is shown in Figure 1:

\section{Model Summary}

\begin{tabular}{cc|c|cc|c} 
Model & $\mathrm{R}$ & R Square & Adjusted R Square & $\begin{array}{c}\text { Std. Error of the } \\
\text { Estimate }\end{array}$ \\
\hline 1 & $.668^{\mathrm{a}}$ & .446 & .248 & .99095 \\
\hline
\end{tabular}

a. Predictors: (Constant), HHI, COMMUNITY, PRICE, MUSIC, CLEAN

ANOVAa

\begin{tabular}{llc|c|c|c|c} 
Model & & Sum of Squares & $\mathrm{df}$ & Mean Square & $\mathrm{F}$ & Sig. \\
\hline \multirow{2}{*}{1} & Regression & 11.052 & 5 & 2.210 & 2.251 & $\mathbf{. 1 0 6}^{\mathbf{b}}$ \\
\cline { 2 - 7 } & Residual & 13.748 & 14 & .982 & & \\
\cline { 2 - 7 } & Total & 24.800 & 19 & & & \\
\hline
\end{tabular}

a. Dependent Variable: FREQUENCYCYC

b. Predictors: (Constant), HHI, COMMUNITY, PRICE, MUSIC, CLEAN 


\begin{tabular}{|c|c|c|c|c|c|c|c|c|c|c|}
\hline \multicolumn{11}{|c|}{ Coefficients $^{a}$} \\
\hline \multirow[b]{2}{*}{ Model } & & \multicolumn{2}{|c|}{ Unstandardized Coefficients } & \multirow{2}{*}{$\begin{array}{c}\text { Standardized } \\
\text { Coefficients } \\
\text { Beta }\end{array}$} & \multirow[b]{2}{*}{$\mathrm{t}$} & \multirow[b]{2}{*}{ Sig. } & \multicolumn{2}{|c|}{$95.0 \%$ Confidence Interval for B } & \multicolumn{2}{|c|}{ Collinearity Statistics } \\
\hline & & B & Std. Error & & & & Lower Bound & Upper Bound & Tolerance & VIF \\
\hline \multirow[t]{6}{*}{1} & (Constant) & 3.737 & 2.992 & & 1.249 & .232 & -2.681 & 10.155 & & \\
\hline & COMMUNITY & .130 & .301 & .095 & .434 & .671 & -.515 & .775 & .823 & 1.216 \\
\hline & MUSIC & .721 & .351 & .433 & 2.052 & .059 & -.033 & 1.475 & .888 & 1.126 \\
\hline & CLEAN & -1.184 & .519 & -.570 & -2.280 & .039 & -2.297 & -.070 & .633 & 1.579 \\
\hline & PRICE & -.010 & .235 & -.008 & -.041 & .968 & -.513 & .494 & .941 & 1.062 \\
\hline & $\mathrm{HHI}$ & -.008 & .159 & -.012 & -.053 & .959 & -.349 & .332 & .750 & 1.333 \\
\hline
\end{tabular}

a. Dependent Variable: FREQUENCYCYC

Figure 1: Multiple-linear regression results

Based on Figure 1, it is observed that using a model containing all five variables is not significant at $\checkmark=.05$ (and just misses significance at $\checkmark=.10$ ), with p-value $=.106$. The model, however, does explain $44.60 \%$ of the variability in $\mathrm{Y}$ as seen by the $\mathrm{R}^{2}$ value. (Recall that $\mathrm{Y}=$ the frequency with which a rider practices indoor cycling.) On the other hand, looking at the individual p-values of each independent variable, music with a p-value of 0.059, and cleanliness with a p-value of 0.039 , would be significant at $\alpha=0.10$. While no proper interpretation can be provided at this point as the general model F-test is not significant, it is indicated that, holding other variables constant, the higher the importance of music to a rider, the more often he/she will tend to practice indoor cycling (positive coefficient). With regards to cleanliness, the higher the importance of this variable to the rider, the less often he/she will tend to practice indoor cycling (negative coefficient). Perhaps a rider who is overly concerned with cleanliness does not, on average, have the same motivation as a rider who finds music very important. Overall, this supports the initial hypothesis that music is a significant variable, but fails to support the proposition that the importance of price is a significant variable.

However, to obtain a clearer picture of which variables have which impact, a stepwise regression analysis needs to be conducted.

\section{Stepwise Regression Analysis}

Stepwise regression results, with the same five variables eligible, are shown in Figure 2.

\section{Model Summary}

\begin{tabular}{c|c|c|c|c} 
Model & $\mathrm{R}$ & R Square & Adjusted R Square & $\begin{array}{c}\text { Std. Error of the } \\
\text { Estimate }\end{array}$ \\
\hline 1 & $.502^{\mathrm{a}}$ & .252 & .211 & 1.01487 \\
\hline 2 & $.662^{\mathrm{b}}$ & .438 & .372 & .90534 \\
\hline
\end{tabular}

a. Predictors: (Constant), CLEAN

b. Predictors: (Constant), CLEAN, MUSIC 
ANOVAa

\begin{tabular}{llc|c|c|c|c} 
Model & & Sum of Squares & df & Mean Square & F & Sig. \\
\hline \multirow{2}{*}{1} & Regression & 6.261 & 1 & 6.261 & 6.079 & $.024^{\mathrm{b}}$ \\
\cline { 2 - 7 } & Residual & 18.539 & 18 & 1.030 & & \\
\cline { 2 - 7 } & Total & 24.800 & 19 & & & \\
\hline 2 & Regression & 10.866 & 2 & 5.433 & 6.629 & $.007^{\mathrm{c}}$ \\
\cline { 2 - 7 } & Residual & 13.934 & 17 & .820 & & \\
\cline { 2 - 7 } & Total & 24.800 & 19 & & & \\
\hline
\end{tabular}

a. Dependent Variable: FREQUENCYCYC

b. Predictors: (Constant), CLEAN

c. Predictors: (Constant), CLEAN, MUSIC

\begin{tabular}{|c|c|c|c|c|c|c|c|c|c|c|}
\hline \multicolumn{11}{|c|}{ Coefficients $^{a}$} \\
\hline \multirow[b]{2}{*}{ Model } & & \multicolumn{2}{|c|}{ Unstandardized Coefficients } & \multirow{2}{*}{$\begin{array}{c}\text { Standardized } \\
\text { Coefficients } \\
\text { Beta } \\
\end{array}$} & \multirow[b]{2}{*}{$t$} & \multirow[b]{2}{*}{ Sig. } & \multicolumn{2}{|c|}{$95.0 \%$ Confidence Interval for B } & \multicolumn{2}{|c|}{ Collinearity Statistics } \\
\hline & & B & Std. Error & & & & Lower Bound & Upper Bound & Tolerance & VIF \\
\hline \multirow[t]{2}{*}{1} & (Constant) & 6.835 & 1.813 & & 3.770 & .001 & 3.026 & 10.644 & & \\
\hline & CLEAN & -1.043 & .423 & -.502 & -2.466 & .024 & -1.933 & -.154 & 1.000 & 1.000 \\
\hline \multirow[t]{3}{*}{2} & (Constant) & 4.500 & 1.894 & & 2.376 & .030 & .505 & 8.495 & & \\
\hline & CLEAN & -1.269 & .389 & -.611 & -3.259 & .005 & -2.090 & -.447 & .940 & 1.063 \\
\hline & MUSIC & .740 & .312 & .444 & 2.370 & .030 & .081 & 1.398 & .940 & 1.063 \\
\hline
\end{tabular}

a. Dependent Variable: FREQUENCYCYC

\section{Excluded Variables ${ }^{a}$}

\begin{tabular}{|c|c|c|c|c|c|c|c|c|}
\hline \multirow[b]{2}{*}{ Mode } & & \multirow[b]{2}{*}{ Beta In } & \multirow[b]{2}{*}{$\mathrm{t}$} & \multirow[b]{2}{*}{ Sig. } & \multirow[b]{2}{*}{$\begin{array}{c}\text { Partial } \\
\text { Correlation }\end{array}$} & \multicolumn{3}{|c|}{ Collinearity Statistics } \\
\hline & & & & & & Tolerance & VIF & $\begin{array}{l}\text { Minimum } \\
\text { Tolerance }\end{array}$ \\
\hline \multirow[t]{4}{*}{1} & $\begin{array}{l}\text { COMMUNI } \\
\text { TY }\end{array}$ & $.142^{\mathrm{b}}$ & .645 & .528 & .155 & .881 & 1.135 & .881 \\
\hline & MUSIC & $.444^{b}$ & 2.370 & .030 & .498 & .940 & 1.063 & .940 \\
\hline & PRICE & $-.077^{b}$ & -.367 & .718 & -.089 & .999 & 1.001 & .999 \\
\hline & HHI & $.048^{\mathrm{b}}$ & .202 & .842 & .049 & .786 & 1.272 & .786 \\
\hline \multirow[t]{3}{*}{2} & $\begin{array}{l}\text { COMMUNI } \\
\text { TY }\end{array}$ & $.092^{\mathrm{c}}$ & .460 & .652 & .114 & .870 & 1.149 & .819 \\
\hline & PRICE & $.005^{c}$ & .024 & .981 & .006 & .964 & 1.037 & .907 \\
\hline & HHI & $.007^{\mathrm{c}}$ & .032 & .975 & .008 & .780 & 1.281 & .760 \\
\hline
\end{tabular}

a. Dependent Variable: FREQUENCYCYC

b. Predictors in the Model: (Constant), CLEAN

c. Predictors in the Model: (Constant), CLEAN, MUSIC

\section{Figure 2: Stepwise regression results}

Figure 2 confirms the findings of Figure 1, showing there are only two significant independent variables; it was possible that additional significant independent variables would "show up" due to multi-colinearity, but this did not occur. The two variables are importance of music and importance of cleanliness of the studio. While music was strongly expected to be a significant variable as stated earlier, cleanliness of the studio was not necessarily expected to be an 
important variable that would strongly affect a rider's decision of practicing indoor cycling at a given studio. In fact, holding the other variables constant, the results indicate the if Music is especially important to a rider, he/she will ride more; if Cleanliness is especially important to the rider, he/she will tend to ride less.

It is important to highlight that the model suggested by the stepwise regression explains $43.80 \%$ of the variability of $\mathrm{Y}$ as shown by the model's $\mathrm{R}^{2}$ value. While this value is, of course, lower (albeit, slightly lower0 than the $\mathrm{R}^{2}$ identified under Figure 1, 44.6\% (since the latter included all 5 variables), the Adjusted $\mathrm{R}^{2}$ went up materially for the model in Figure 2 (to .372, from the Figure 1 Adjusted $\mathrm{R}^{2}$ value of .248), indicating that this latter model can be viewed as a superior model to that of Figure 1 . Additionally, the $\mathrm{p}$-value for the $\mathrm{F}$ statistic for the overall model in Figure 2 is .007 , way below the earlier mentioned Figure 1 value of .106.

Despite the fact that the stepwise regression did not include community, price, and HHI, we chose to include importance of [the sense of] community in what we wish to think of as the "final model." This is because community can be considered as a variable that impacts someone's experience at a studio, and experience, as the study from Nicolao et al. (2009) indicates, is the main reason why people are more willing to spend money. Hence, our suggested final model, based on running a multiple regression with the three aforementioned independent variables (importance of cleanliness, importance of music and importance of community), is

$$
\text { Y-predicted }=4.50-1.269 X_{1}+0.740 X_{2}+0.092 X_{3}
$$

where $X_{1}$ is the importance of cleanliness of the studio, $X_{2}$ is the importance of music, and $X_{3}$ is importance of community.

\section{LIMITATIONS AND DIRECTIONS FOR FUTURE RESEARCH}

While the results of this study helped identify factors that influence a rider's frequency in practicing indoor cycling, the study suffers from some major limitations that can be addressed in a future study. For this analysis, only twenty responses were recorded as not every rider at FireCycle wished to participate. As a result, the sample is much too small to be a definitive study on the subject. To address this issue, the survey could be sent electronically to riders in the studio's database with the permission of the owner. This would allow access to a larger number of riders, and the riders would be able to fill out the questionnaire at their leisure in, perhaps, a more comfortable setting. Both the larger sample size and conditions of filling out the questionnaire would likely help improve the accuracy of the results of the regression analyses. In addition, results could be collected over a larger time span, and make the survey available to riders of other studios, to ensure a wide range of responses that could help validate a future model.

Another limitation of this study was the set of independent variables chosen. For this research only five independent variables were selected based on a conversation with the owner of FireCycle about which factors are likely to impact a rider's experience and willingness to practice indoor cycling more vs. less frequently. This could have been, to an extent, biased, and therefore, further research should be conducted to determine if there are any other independent variables that should be included. Perhaps, a focus group would be useful to identify additional variables. 


\section{References}

Barua, Akrur, and Daniel Bachman (2017). “The Consumer Rush to 'Experience': Truth or Fallacy?" Deloitte United States, 18 Aug. 2017, www2.deloitte.com/insights/us/en/economy/behind-the-numbers/are-consumersspending-more-on-experience.html.

Boven, Leaf Van, and Thomas Gilovich (2003). To Do or to Have? That Is the Question. American Psychological Association, psych.colorado.edu/ vanboven/research/publications/vb_gilo_2003.pdf.

Cohen, Anya (2018). “Gym, Health \& Fitness Clubs in the US.” IBISWorld, July, clients1.ibisworld.com/reports/us/industry/default.aspx?entid=1655.

Deshpande, Rohit (2014). “Customer Centricity." Harvard Business Publishing, 30 June, hbsp.harvard.edu/download?url=\%2Fcourses\%2F559289\%2Fitems\%2F8171-PDFENG\%2Fcontent\&metadata $=\mathrm{e} 30 \% 3 \mathrm{D}$.

FireCycle (2018). "FireCycle Studio." FireCycle, firecyclestudio.com/.

Harmon, Nicole M, and Len Kravitz (2007). “The Beat Goes On: The Effects of Music on Exercise.” Www.ideafit.com, 1 Sept., www.ideafit.com/fitness-library/beat-goes-effects-music-exercise.

Leve, Chuck (2016). "Latest Research: Cycling Studios Generate 55\% More Revenue Than Other Fitness Studios." The Association of Fitness Studios, 12 Sept., member.afsfitness.com/content/latest-research-cycling-studiosgenerate-55\%C2\%A0more-revenue-other-fitness-studios.

Midgley, Ben (2018). "The Six Reasons The Fitness Industry Is Booming." Forbes, Forbes Magazine, 26 Sept., www.forbes.com/sites/benmidgley/2018/09/26/the-six-reasons-the-fitness-industry-isbooming/\#3cde2bc506db.

Nicolao, Leonardo, Irwin, Julie, and Joseph Goodman (2009). "Happiness for Sale: Do Experiential Purchases Make Consumers Happier than Material Purchases?” Oxford Journals, Aug., www.jstor.org/stable/pdf/10.1086/597049.pdf?refreqid=excelsior\%3A77daed4230512d598263533420047ad5. Peloton (2018). "Peloton Bike Experience.” Peloton®, www.onepeloton.com/shop/bike.

SoulCycle (2018). “SoulCycle Classes.” SoulCycle, www.soul-cycle.com/series/. 